\title{
A Catecholaminergic Sensory Neuron Phenotype in Cranial Derivatives of the Neural Crest: Regulation by Cell Aggregation and Nerve Growth Factor
}

\author{
David M. Katz \\ Department of Neurosciences, Case Western Reserve University School of Medicine, and Department of Medicine, \\ University Hospitals of Cleveland, Cleveland, Ohio 44106
}

Tyrosine hydroxylase (TH) is transiently detectable in cells distributed throughout cranial sensory ganglla during early stages of gangliogenesis [embryonic day (E) 10.5-15.5]. Although TH cells appear in embryonic ganglia of both neural crest and placode origin, mature cranial sensory neurons that express catecholaminergic properties are restricted to placode derivatives. The mechanism(s) underlying the loss of TH expression in crest-derived sensory ganglia is unknown, and the present study was undertaken to define the temporal regulation of this phenotype. Our data indicate that transient TH cells belong to a large subset of primary sensory neurons that exhibit the capability to express TH throughout development. The lack of TH expression after E15.5 appears to be due to modulation of this catecholaminergic potential. The phenotype reappears, however, when E16.5 and older ganglia are dissociated in culture into single cells, suggesting that factors associated with cell aggregation modulate TH expression. In support of this hypothesis, sensory neurons grown at high cell density exhibit lower levels of TH expression than low-density cultures. The decrease in TH levels seen at high density was associated with changes in sensory neuron morphology that are characteristic of ganglion cell maturation in vivo; therefore, modulation of TH expression may be only one facet of a more general program of sensory neuron differentiation associated with cell aggregation in developing ganglia. In contrast to the effects of cell aggregation, treatment with NGF increased the proportion of TH cells in dissociate cultures of E14.5 and E16.5 cranial sensory ganglia. Our findings indicate that sensory transmitter phenotype may be modulated by multiple factors during gangliogenesis, including cellular interactions intrinsic to the developing ganglionic microenvironment.

Peripheral sensory neurons exhibit marked phenotypic heterogeneity characterized by differences in size, morphology, and electrical properties and by expression of diverse transmitter traits and cell surface molecules (Lawson et al., 1974; Rambourg

\footnotetext{
Received May 21, 1991; revised July 29, 1991; accepted July 30, 1991

I thank Melissa Erb, Emily Rayes, Hua He Jun, and Cherlyn Miller for their valuable contributions to this study, and Story Landis for insightful comments on the manuscript. This work was supported by Grant HL-42131 from NIH and by the Dysautonomia Foundation.

Correspondence should be addressed to David M. Katz, Ph.D., Department of Neurosciences, Case Western Reserve University School of Medicine, 2119 Abington Road, Cleveland, $\mathrm{OH} 44106$.

Copyright (C) 1991 Society for Neuroscience $0270-6474 / 91 / 113991-12 \$ 05.00 / 0$
}

et al., 1983; Dodd and Jessell, 1985; Marusich et al., 1986a; Regan et al., 1986). In some instances, expression of specific traits by subpopulations of sensory neurons is correlated with innervation of a specific peripheral target (Katz and Black, 1986) or with patterns of afferent connections within the CNS (Nagy and Hunt, 1982, 1983; Regan et al., 1985). In addition, some phenotypes are spatially segregated along the sensory neuraxis in a ganglion-specific manner (Dodd and Jessell, 1985; Marusich et al., 1986b), particularly at cranial levels.

One of the most striking examples of a ganglion-specific pattern of expression is the restricted localization of catecholaminergic (CA) primary sensory neurons. These cells express catalytically active tyrosine hydroxylase (TH; Katz et al., 1983), dopa decarboxylase (D. M. Katz, unpublished observations), and catecholamine histofluorescence (Katz et al., 1983) and are found almost exclusively in the nodose, petrosal (Katz et al., 1983), and geniculate (Katz, unpublished observations) ganglia of adult mammals (Fig. 1). CA sensory neurons are not found in other cranial sensory ganglia and, with rare exception (Price and Mudge, 1983), are also absent from most dorsal root ganglia (DRG).

Although cells that express CA properties exhibit highly restricted distributions in mature sensory ganglia, this is not true during development. $\mathrm{TH}$, for example, is transiently expressed by cells distributed throughout the cranial and spinal sensory neuraxis in rat embryos (Jonakait et al., 1984; Katz and Erb, 1990a). Thus, TH-immunoreactive cells are found in the trigeminal (Jonakait et al., 1984), geniculate (Katz, unpublished observations), jugular-superior, petrosal, nodose, and cervical dorsal root ganglia in the rat, between 10.5 and $15.5 \mathrm{~d}$ of gestation (Fig. 1; Jonakait et al., 1984; Katz and Erb, 1990a). This is in sharp contrast to the limited distribution of TH-containing neurons in adult animals. A notable difference between the embryonic and mature patterns of $\mathrm{TH}$ expression is that ganglia in which the phenotype is only transiently expressed contain sensory neurons of neural crest origin (i.e., the trigeminal, jugular-superior, and dorsal root ganglia). This suggests that the ability to express CA traits may be a widespread feature of crestderived cells in mammalian sensory ganglia during early embryogenesis.

Mechanisms underlying the loss of CA properties in crestderived sensory ganglia are unknown. One possibility is that early $\mathrm{TH}$ cells die or migrate away from the ganglia during embryogenesis. Alternatively, initial expression of TH may subsequently decline in an otherwise stable population of cells, resulting in the more limited distribution of the phenotype in 


\section{E10.5-15.5}

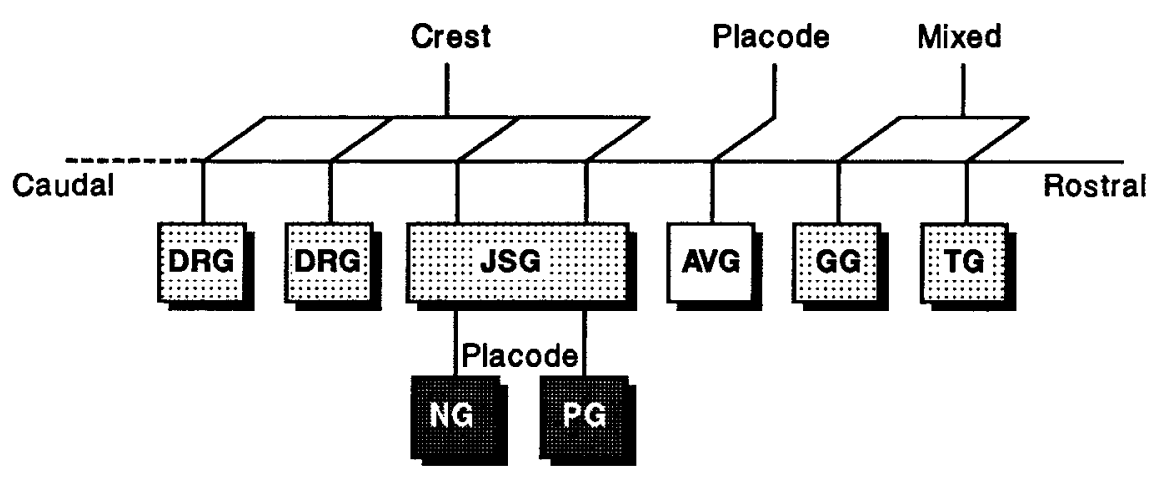

Figure 1. Schematic diagram illustrating the relative distribution of THcontaining cells (shading) in embryonic and adult cranial sensory ganglia of the rat. $T G$, trigeminal ganglion; $G G$, geniculate ganglion; $A V G$, acousticovestibular ganglion; $P G$, petrosal ganglion; $J S G$, jugular-superior ganglion; $N G$, nodose ganglion; $D R G$, cervical dorsal root ganglia. Crest, Placode, and Mixed indicate the presumed embryonic origin of each ganglion based on fate-mapping studies in chick embryo chimeras (LeDouarin et al., 1981; see also Johnston, 1966; Weston, 1970; Noden, 1978; Narayanan and Narayanan, 1980; D'Amico-Martel and Noden, 1983) and histologic studies of normal rat embryos (Adelman, 1925; Batten, 1957). Top, E10.5-15.5 (Jonakait et al., 1984; Katz and Erb, 1990a); bottom. E16.5-adult animals. Density of shading indicates the relative abundance of TH-containing cells.

\section{E16.5-Adult}

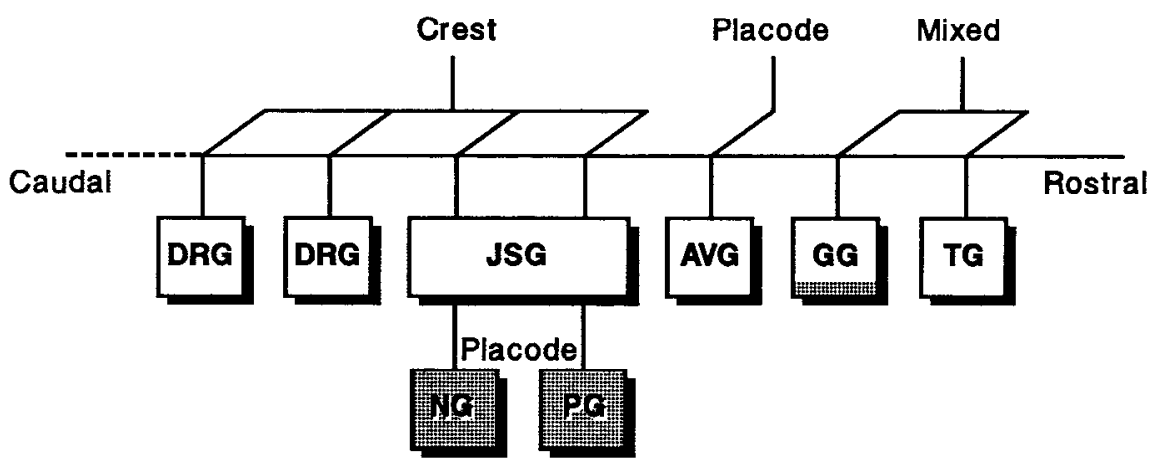

maturity. The present study was undertaken to distinguish among these possibilities by examining mechanisms of CA regulation at different stages of development of crest-derived sensory ganglion cells.

A portion of these results has previously been published in abstract form (Katz and Erb, 1990b).

\section{Materials and Methods}

Cell and tissue cultures. Explant and dissociated cell cultures of embryonic and newborn jugular-superior ganglia (JSG) and DRG from SpragueDawley rat embryos (Zivic-Miller) were grown in Leibovitz's $\mathrm{L}-15 / \mathrm{CO}_{2}$ medium containing 10\% NuSerum (Collaborative Research), $7.5 \%$ heatinactivated fetal bovine serum (GIBCO), fresh vitamin mixture (Mains and Patterson, 1973), and penicillin/streptomycin (50 IU/ml; $50 \mu \mathrm{g} /$ $\mathrm{ml})$. Ganglia were enzymatically dissociated by incubation in Dispase (Collaborative Research; diluted 1:1 in calcium-, magnesium-free phosphate-buffered saline) for $1 \mathrm{hr}$ at $37^{\circ} \mathrm{C}$, followed by trituration through fire-polished Pasteur pipettes. Explants and dissociates were plated onto acid-washed glass coverslips coated with polylysine $(0.1 \mathrm{mg} / \mathrm{ml})$ and laminin $(0.3 \mu \mathrm{g} / \mathrm{ml})$ in plastic multiwell tissue culture plates. NGF was prepared according to the protocols of Smith et al. (1969) and Stach et al. (1977) and was generously provided by Dr. Kenneth Neet (Chicago Medical College). For experiments involving mitotic labeling, dissociated cell cultures were incubated for $24 \mathrm{hr}$ with bromodeoxyuridine (BrdU; 1:100; Collaborative Research) and then fixed for immunocytochemical staining as described below.
Immunocytochemistry. After appropriate times in culture, explants and dissociated cells were rinsed with serum-free culture medium and then fixed sequentially in $4 \%$ paraformaldehyde in $0.1 \mathrm{~m}$ sodium acetate buffer, $\mathrm{pH} 6.5$, for $10 \mathrm{~min}$ followed by $4 \%$ paraformaldehyde in $0.1 \mathrm{M}$ sodium borate buffer, $\mathrm{pH} 10.5$, for $20 \mathrm{~min}$. Cultures were then rinsed in several changes of phosphate-buffered saline (PBS) and processed for either single or double immunostaining as described below. In some cases, explant cultures were sectioned at $10 \mu \mathrm{m}$ in a cryostat prior to immunostaining. The following immunocytochemical reagents were used: polyclonal anti-TH (1:200, Pel-Freez), monoclonal anti-substance $\mathrm{P}$ (anti-SP) (1:2000; Incstar), monoclonal anti-BrdU (1:100; Becton Dickinson), monoclonal anti-neurofilament proteins 200,160 , and 68 (antiNF; 1:40; Sigma), monoclonal antibody SA1 (undiluted supernatant; Anderson et al., 1991; Carnahan and Patterson, $1991 \mathrm{a}, \mathrm{b}$ ), goat antirabbit IgG-fluorescein isothiocyanate (1:200; Boehringer Mannheim), and sheep anti-mouse IgG-rhodamine (1:200; Cappel). For single immunostaining with anti-TH, cultures were (1) incubated overnight at room temperature in primary antisera diluted in PBS containing $0.5 \%$ Triton X-100, (2) washed three times in PBS, (3) incubated for $1 \mathrm{hr}$ at room temperature in secondary antisera diluted in PBS-Triton containing $10 \%$ goat serum, (4) washed in PBS, (5) incubated in $p$-phenylenediamine (PDA; $1 \mathrm{mg} / \mathrm{ml}$ ) for $1 \mathrm{~min}$, and (6) coverslipped with glycerol gel. For double immunostaining with anti-TH plus anti-BrdU, cultures were treated as in steps $1-6$ above and then (7) fixed for 30 $\mathrm{min}$ at room temperature in $0.5 \%$ paraformaldehyde in $0.1 \mathrm{M}$ sodium phosphate buffer, (8) washed with PBS and then treated with $2 \mathrm{~N} \mathrm{HCl}$ for $20 \mathrm{~min}$ at room temperature to permeabilize DNA, (9) washed and incubated for $30 \mathrm{~min}$ at room temperature in anti-BrdU diluted in PBSTriton containing $20 \%$ goat serum, (10) washed and incubated for 30 

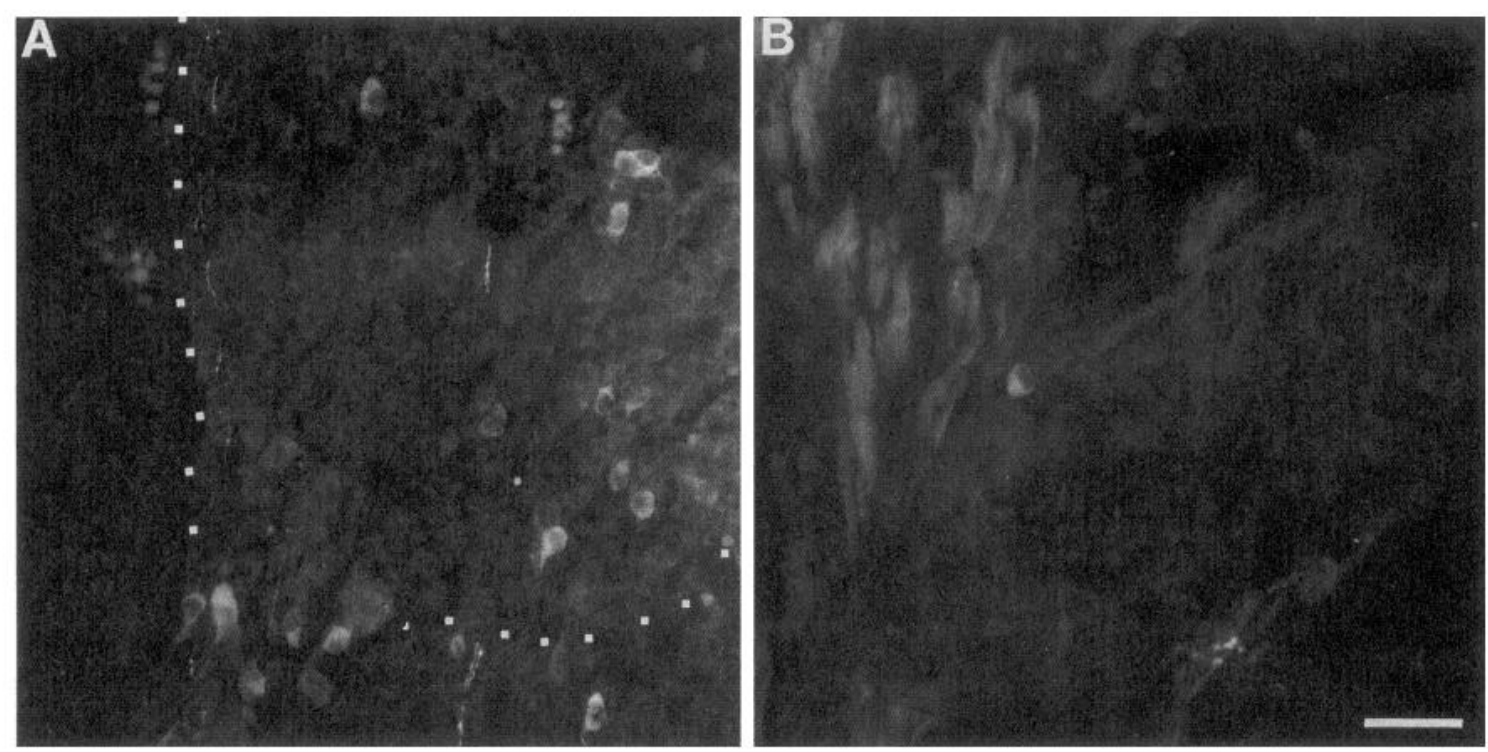

Figure 2. Fluorescence photomicrographs of TH-immunoreactive cells in tissue sections through the E14.5 $(A)$ and E16.5 (B) JSG. In $A$, squares indicate the approximate lateral margins of the developing ganglion. In both figures, the dorsal attachment of the ganglia to the brainstem is to the upper right (out of view). Scale bar, $40 \mu \mathrm{m}$.

$\mathrm{min}$ at room temperature in secondary antiserum diluted in PBS-Triton containing $10 \%$ goat serum, and (11) washed, treated with PDA, and coverslipped as above. For double immunostaining with anti-TH and anti-SP or anti-NF, cultures were treated as in steps $1-6$ above and subsequently stained for the second antigen using the same protocol with the following modifications: (1) incubations with anti-NF were carried out for only $1 \mathrm{hr}$ at room temperature, and (2) the concentration of goat serum in secondary antisera was increased to $20 \%$. Cell counts were obtained by direct microscopic observation of immunostained cultures with $20 \times$ and $40 \times$ objectives.

Gel electrophoresis and Western blots. Cultures were harvested by aspiration with a micropipette, suspended in 25-50 $\mu$ l Laemmli buffer (Laemmli, 1970), and boiled for 3-9 min. Boiling was sufficient to dissolve the ganglia without additional homogenization. The homogenates were then fractionated by sodium dodecyl sulfate (SDS)-polyacrylamide gel electrophoresis on minigels (Hoefer Scientific) using Rainbow Marker molecular weight standards (Collaborative Research). Fractionated proteins were electrotransferred to nitrocellulose in Trisglycine buffer $(\mathrm{pH} 8.3)$ containing $0.01 \%$ SDS and probed with either monoclonal (1:1000; Boehringer Mannheim) or polyclonal (1:200; Incstar) anti-TH. Bound antibody was visualized by staining with a streptavidin-biotin-horseradish peroxidase (ABC) kit (Vector Labs) using 4-chloronaphthol as a substrate.

\section{Results}

\section{Transient TH cells in cranial sensory ganglia are primary} sensory neurons

To examine mechanisms of catecholaminergic phenotypic expression during cranial sensory development, the present study focused on the fused JSG of cranial nerves IX and X (Fig. 1). The JSG, also known as the proximal, or root ganglion of the IX-X complex, arises during the lateral migration of cells from the rhombencephalic neural crest. Studies of avian embryo chimeras demonstrated that all JSG neurons are of crest origin (LeDouarin et al., 1981; see also Johnston, 1966; Weston, 1970; Noden, 1978; Narayanan and Narayanan, 1980; D'Amico-Martel and Noden, 1983); most studies in rat (Adelman, 1925) and sheep (Batten, 1957) support a similar origin in mammals (see however Altman and Bayer, 1982).

The JSG is first recognizable on embryonic day (E) 13.5 as a loose aggregation of cells, caudal to the otic vesicle, associated with the extracranial rootlets of the glossopharyngeal and vagal nerves. A few TH cells were found scattered among the JSG neurons at this age. By E14.5, TH cells were more numerous and were found both within the JSG and dispersed in the mesenchyme at the margins of the developing ganglion (Fig. $2 A$ ). By E16.5, the ganglion has coalesced into a well-defined cell cluster, and TH-positive neurons were only rarely seen at this and subsequent ages (Fig. 2B). Initial studies sought to characterize the cellular phenotype of the transient TH population and to determine whether or not they were sensory neurons. This was important because multiple crest derivatives, including sympathoadrenal cells and enteric neuronal precursors (Baetge et al., 1990a,b), also express TH. Even non-neuronal cells may express some CA traits, such as catecholamine uptake, during early development (Rohrer, 1985). To begin characterizing the early, transient TH cells, we first examined whether they were differentiating along a neuronal lineage or, alternatively, were uncommitted precursor or non-neuronal cells. Immunohistochemical studies of tissue sections through the E14.5 JSG demonstrated neurofilament protein immunoreactivity in TH-containing ganglion cells (Fig. 3), consistent with a neuronal phenotype. To delineate the morphology of these cells better, ganglia were grown in dissociated cell culture for $24 \mathrm{hr}$ and then double stained with anti-TH and anti-NF protein antibodies. In dissociate cultures, $\mathrm{TH}$-immunoreactive perikarya exhibited NF protein immunoreactivity (Fig. 4), as in vivo. The TH cells were primarily bipolar and, except for their $\mathrm{TH}$ content, were morphologically indistinguishable from other $\mathrm{NF}^{+}$cells in the cultures. $\mathrm{TH}^{+} / \mathrm{NF}^{+}$cells comprised approximately $10 \%$ of the total $\mathrm{NF}^{+}$population (Table 1).

To determine whether the TH cells in E14.5 JSG cultures were dividing neuronal precursors or, alternatively, postmitotic neurons, ganglia were grown for $24 \mathrm{hr}$ in dissociate cell culture in the presence of BrdU to label dividing cells. BrdU is stably incorporated into the nuclei of cells undergoing DNA synthesis. Cultures were then double stained with antisera against TH and $\mathrm{BrdU}$ and analyzed for the percentage of cells exhibiting both 

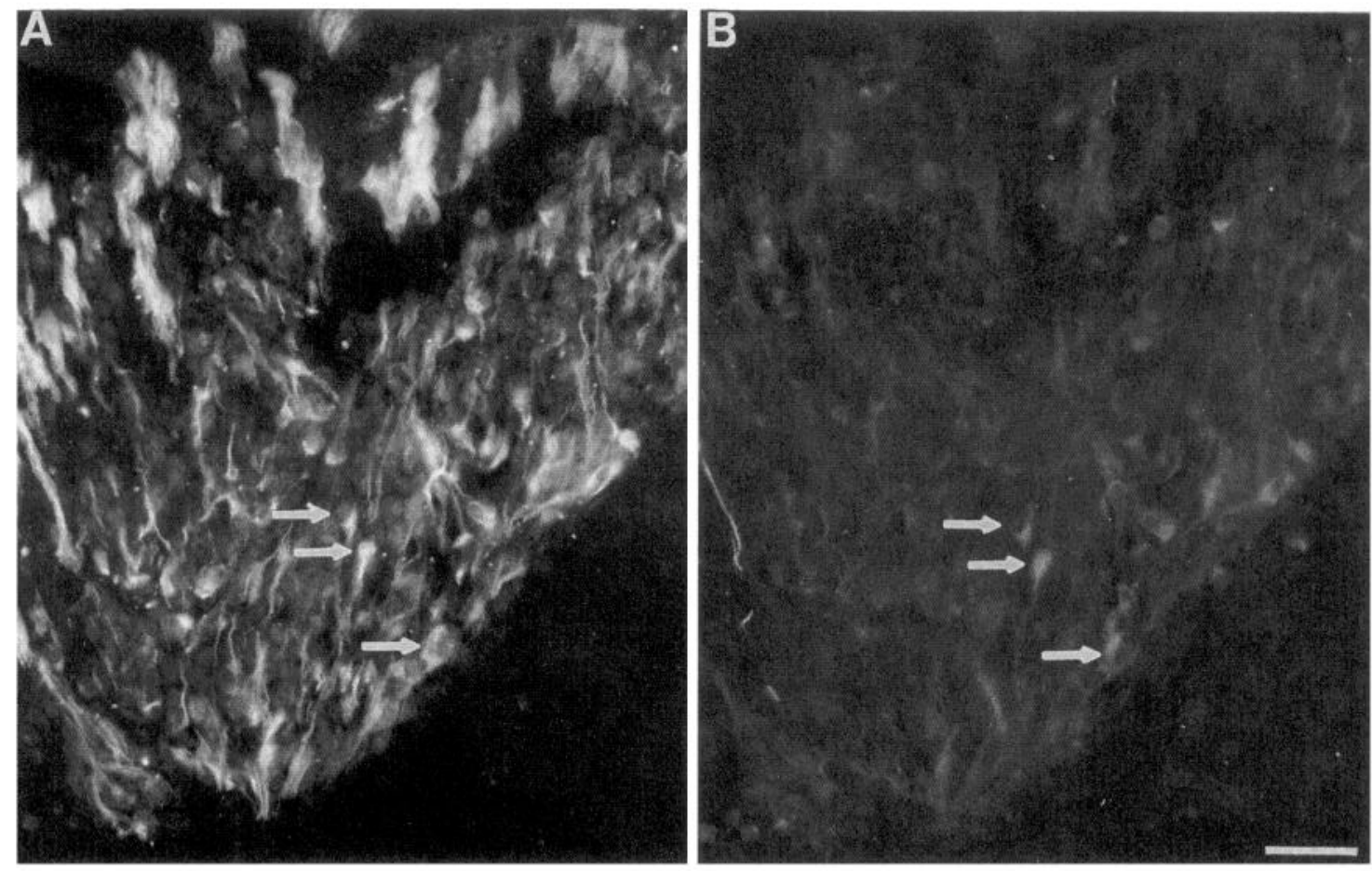

Figure 3. Fluorescence photomicrographs showing double staining for NF proteins $(A)$ and TH $(B)$ in a tissue section through an E14.5 JSG. Arrows indicate double-labeled neurons. Scale bar, $40 \mu \mathrm{m}$.

markers. Analysis of 350 TH-positive neurons revealed no cells with nuclear BrdU staining (Fig. $5 A$ ). In contrast, a large proportion of non-neuronal cells, which actively divide in culture, were stained by anti-BrDU antiserum (Fig. $5 B$ ). On the basis of these experiments, we concluded that the TH-containing cells in JSG cultures were postmitotic neurons and that ongoing mitosis was not required for expression of this phenotype.

$\mathrm{TH}$ expression is a trait that embryonic JSG neurons share in common with other crest derivatives, including sympathoadrenal cells and enteric neuronal precursors (Baetge and Gershon, 1990a,b; Anderson et al., 1991; Carnahan and Patterson, 1991a,b), raising the possibility that the TH neurons in our cultures were differentiating along an autonomic, rather than a sensory, neuronal lineage. To approach this issue, we examined whether JSG TH cells exhibit immunoreactivity to monoclonal antibody SA1 (Anderson et al., 1991; Carnahan and Patterson, 1991a,b), which recognizes an epitope expressed by embryonic cells in the sympathoadrenal and enteric neuronal lineages. In these experiments, immunoreactivity was examined in tissue sections of E14.5 JSG in situ. As previously reported (Anderson et al., 1991; Carnahan and Patterson, 1991a,b), abundant SA1 immunoreactivity was observed in the developing sympathetic
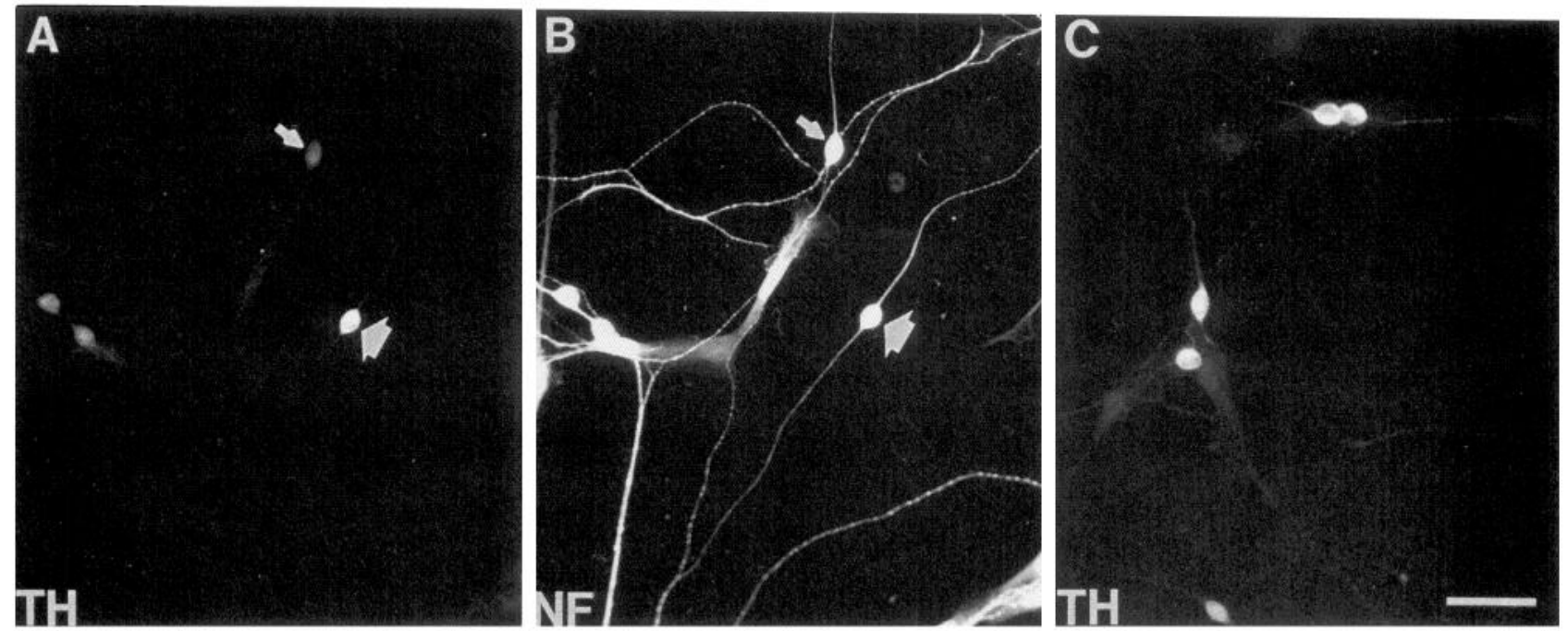

Figure 4. Fluorescence photomicrographs of E14.5 JSG neurons grown for $24 \mathrm{hr}$ in dissociate cell culture. $A$ and $B$ show the same cells double immunostained for TH $(A)$ and NF proteins $(B)$. Large arrows indicate a double-labeled $\left(\mathrm{TH}^{+} / \mathrm{NF}^{+}\right)$bipolar neuron; small arrow is pointing to $\mathrm{TH}^{-} / \mathrm{NF}^{+}$neurona. $C$, TH neurons from a different field than that shown in $A$ and $B$. Scale bar, $40 \mu \mathrm{m}$. 

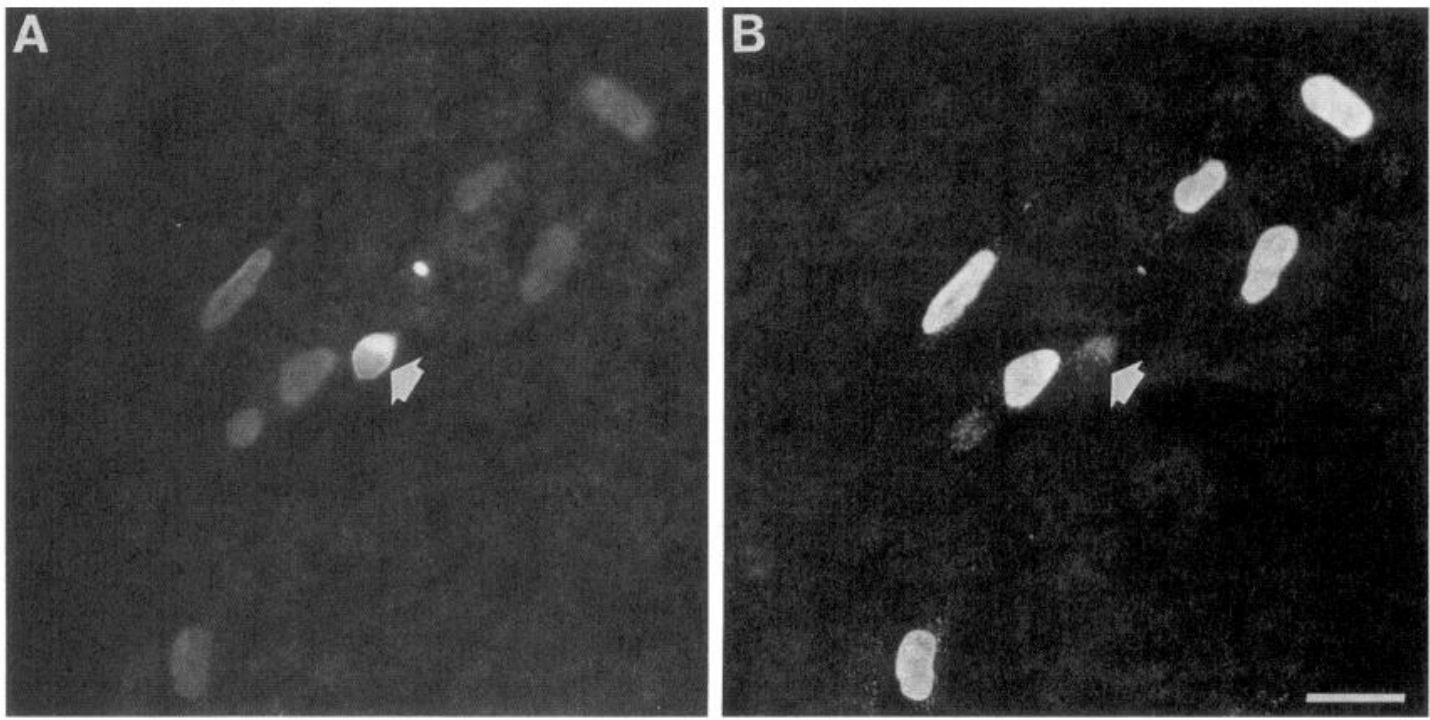

Figure 5. Fluorescence photomicrographs of E14.5 JSG cells grown for $24 \mathrm{hr}$ in dissociate cell culture and double immunostained for TH (A) and BrdU $(B)$. Cultures were exposed to BrdU (1:100) during the entire $24 \mathrm{hr}$ culture period. Arrow indicates a TH-positive neuron $(A)$ that lacks nuclear BrdU staining $(B)$. In contrast, non-neuronal cells surrounding the neuron exhibit intense BrdU immunoreactivity in their nuclei $(B)$. Scale bar, $20 \mu \mathrm{m}$.

chain of E14.5 embryos. In contrast, no stained cells were seen in the JSG or in any other sensory ganglia at this age (Fig. 6). Similarly, no SA1 staining was seen in TH-containing neurons in JSG cultures (data not shown). The absence of SA1 staining in sensory TH neurons demonstrates that these cells do not share this specific lineage marker with sympathoadrenal cells, suggesting that the two populations have distinct developmental histories. Similarly, the JSG TH cells are distinct from enteric neuronal precursors that also express the SA1 epitope (Carnahan and Patterson, 1991a,b; Katz, unpublished observations) as well as TH (Baetge and Gershon, 1990a,b).

Morphologic studies of JSG neurons in long-term explant cultures provided further evidence that the $\mathrm{TH}$ cells were sensory neurons. In these experiments, we took advantage of the fact that TH expression was maintained in E14.5 JSG neurons grown for up to $5 \mathrm{~d}$ in culture. During this period, the TH neurons exhibited a pattern of morphologic maturation similar to that of sensory neurons in vivo. Specifically, they acquired unipolar morphologies characteristic of fetal sensory neurons (Fig. 7). In addition, some TH cells coexpressed SP-like immunoreactivity, a trait associated with many neurons in the mature JSG (Fig. 8).

Table 1. Proportion of TH neurons in E14.5 and 16.5 JSG dissociated cell cultures in the presence or absence of NGF

\begin{tabular}{lcll} 
& $\mathrm{TH}^{+a}(n)$ & $\mathrm{NF}^{+b}(n)$ & $\begin{array}{l}\mathrm{TH}^{+} / \mathrm{NF}^{+} \\
\times 100 \%\end{array}$ \\
\hline E14.5 control & $333 \pm 63(8)$ & $3376 \pm 497(8)$ & $10 \%$ \\
E14.5 + NGF & $1234 \pm 113(11)$ & $5223 \pm 754(11)$ & $24 \%$ \\
E16.5 control & $30 \pm 9(10)$ & $144 \pm 34(10)$ & $21 \%$ \\
E16.5 + NGF & $681 \pm 116(8)$ & $1586 \pm 253(8)$ & $44 \%$
\end{tabular}

Each value represents the mean \pm SEM of cell counts per culture well from $n$ cultures, plated at a density of approximately 2 JSG per well.

${ }^{a} \mathrm{TH}-\mathrm{immunoreactive} \mathrm{neurons.}$

${ }^{b}$ Total number of neurons, visualized by NF protein immunoreactivity.

\section{NGF stimulates TH expression in embryonic cranial sensory ganglia}

The presence of small numbers of TH sensory neurons in the embryonic JSG suggested that only a small subpopulation of ganglion cells was capable of expressing a CA phenotype. Alternatively, only a small subpopulation may normally express $\mathrm{TH}$ at levels above the threshold for immunostaining. We therefore sought to determine whether TH expression in JSG sensory neurons could be augmented by exogenous factors known to increase $\mathrm{TH}$ levels in other populations. During early development, for example, TH expression in peripheral autonomic neurons is stimulated by exposure to exogenous NGF (Kessler and Black, 1980). To determine whether TH could be similarly regulated in embryonic sensory ganglion cells, E14.5 JSG were grown for $24 \mathrm{hr}$ in explant and dissociated cell culture in the presence or absence of $20 \mathrm{ng} / \mathrm{ml} \mathrm{NGF}$ and monitored for TH expression by immunocytochemical staining and Western blotting. NGF treatment elicited a marked increase in the proportion of TH neurons in both explants and dissociates. In the presence of $\mathrm{NGF}, \mathrm{TH}^{+} / \mathrm{NF}^{+}$neurons comprised $23 \%$ of the total $\mathrm{NF}^{+}$ population in dissociate cultures compared to approximately $10 \%$ in controls (Table 1). Immunoblot analysis of JSG explant homogenates confirmed that the immunoreactivity in these cultures was associated with authentic TH (not shown). These data

\begin{tabular}{|c|c|c|}
\hline & $\mathrm{TH}^{+}(n)$ & $\mathrm{NF}^{+}(n)$ \\
\hline Control & $551 \pm 89(5)$ & $3027 \pm 407(5)$ \\
\hline Anti-NGF & $657 \pm 97(5)$ & $2082 \pm 442(5)$ \\
\hline
\end{tabular}

Each value represents the mean \pm SEM of cell counts per culture well from $n$ cultures, plated at a density of approximately 2 JSG per well. 
Figure 6. Fluorescence photomicrographs of tissue sections through a JSG (A) and a superior cervical sympathetic ganglion (SCG; $B$ ) from the same E14.5 embryo stained with monoclonal antibody $1 \mathrm{~A} 11$. SCG cells exhibit intense $1 \mathrm{Al1}$ immunoreactivity, whereas no stained cells are present in the JSG. Scale bar, $40 \mu \mathrm{m}$.
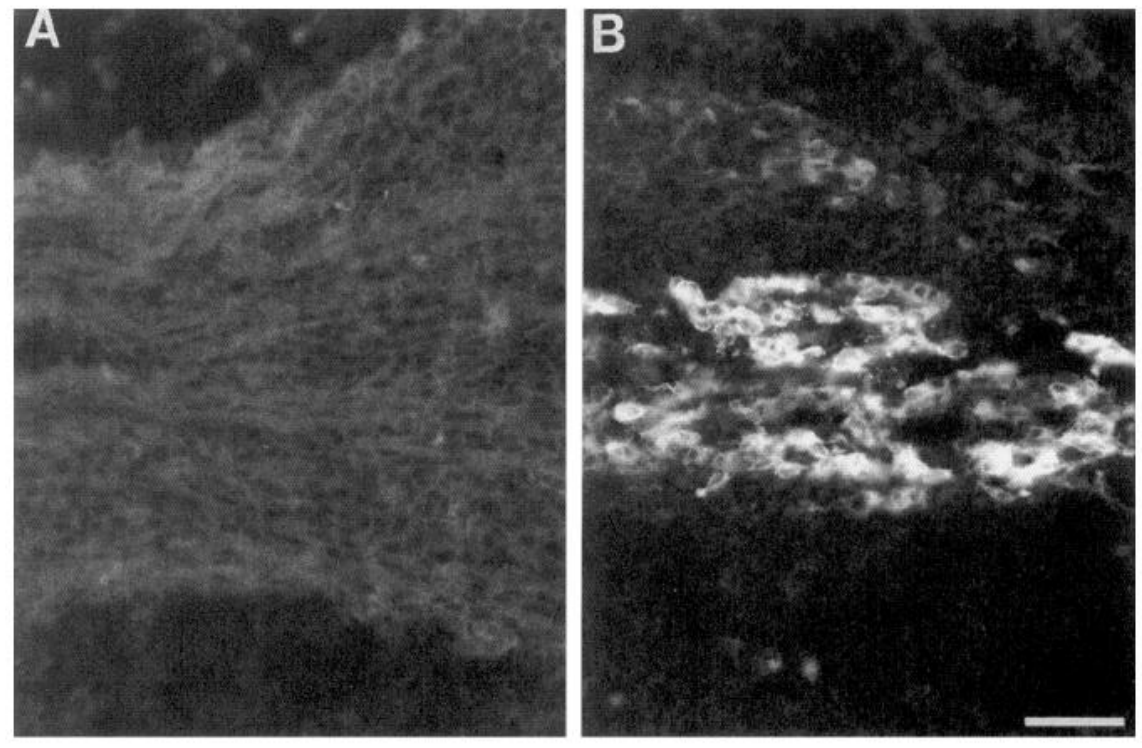

demonstrated that at E14.5, when relatively small numbers of TH cells could be detected in the JSG in situ, NGF treatment in vitro resulted in high levels of $\mathrm{TH}$ expression by a large proportion of ganglion neurons. NGF did not, however, appear to be required for TH expression since control cultures, grown in the absence of NGF, contained approximately $10 \% \mathrm{TH}^{+}$neurons. Nonetheless, to rule out the possibility that control cultures contained endogenous NGF that stimulated basal levels of TH, ganglion dissociates were grown in the presence or absence of antiserum directed against the biologically active $\beta$-subunit of $\mathrm{NGF}$ and monitored for TH immunoreactivity. Treatment with anti-NGF decreased total neuronal survival (Table 2), indicating that endogenous NGF, or an NGF-like molecule, was active in the culture system. However, the number of $\mathrm{TH}^{+}$neurons did not decrease (and was, in fact, slightly elevated in antibodytreated cultures; Table 2), making it unlikely that the TH seen under control conditions was due to stimulation by NGF. Moreover, the fact that $\mathrm{TH}$ cell numbers did not fall in proportion to total neuronal survival with anti-NGF indicates that the TH cells in the E14.5 ganglion are less dependent on NGF at this age than the ganglion cell population as a whole.

\section{"TH-competent" neurons persist in cranial sensory ganglia after the period of transient expression in vivo}

In contrast to the E13.5 and E14.5 ganglion, only rare THpositive cells are found in the JSG at E16.5 and later in vivo. Our initial studies of ganglion development in situ indicated that this change in $\mathrm{TH}$ expression coincided with a change in the state of aggregation of the developing sensory ganglia. Specifically, transient TH cells were found dispersed around the margins of the developing ganglia and appeared to be migrating (Fig. 2), whereas older ganglia appeared more condensed. Similar observations were made in ganglion explants. For example, E14.5 cells migrated extensively in culture; within a few hours after explantation, large numbers of neurons were found several hundred microns away from the main ganglion mass (Fig. 9A).
Figure 7. Fluorescence photomicrograph of TH-immunoreactive neurons in an E14.5 JSG explant maintained for $5 \mathrm{~d}$ in tissue culture. Three stained cells that exhibit unipolar morphologies characteristic of sensory neurons can be seen (arrows). Scale bar, $40 \mu \mathrm{m}$.

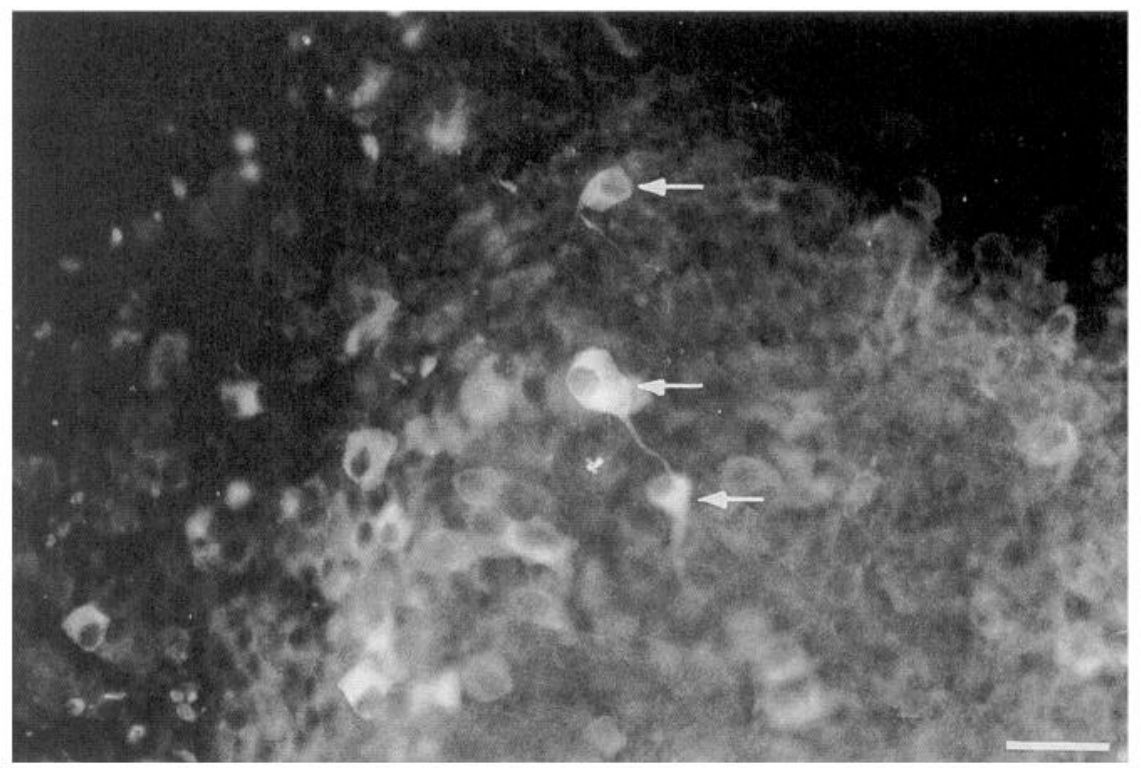



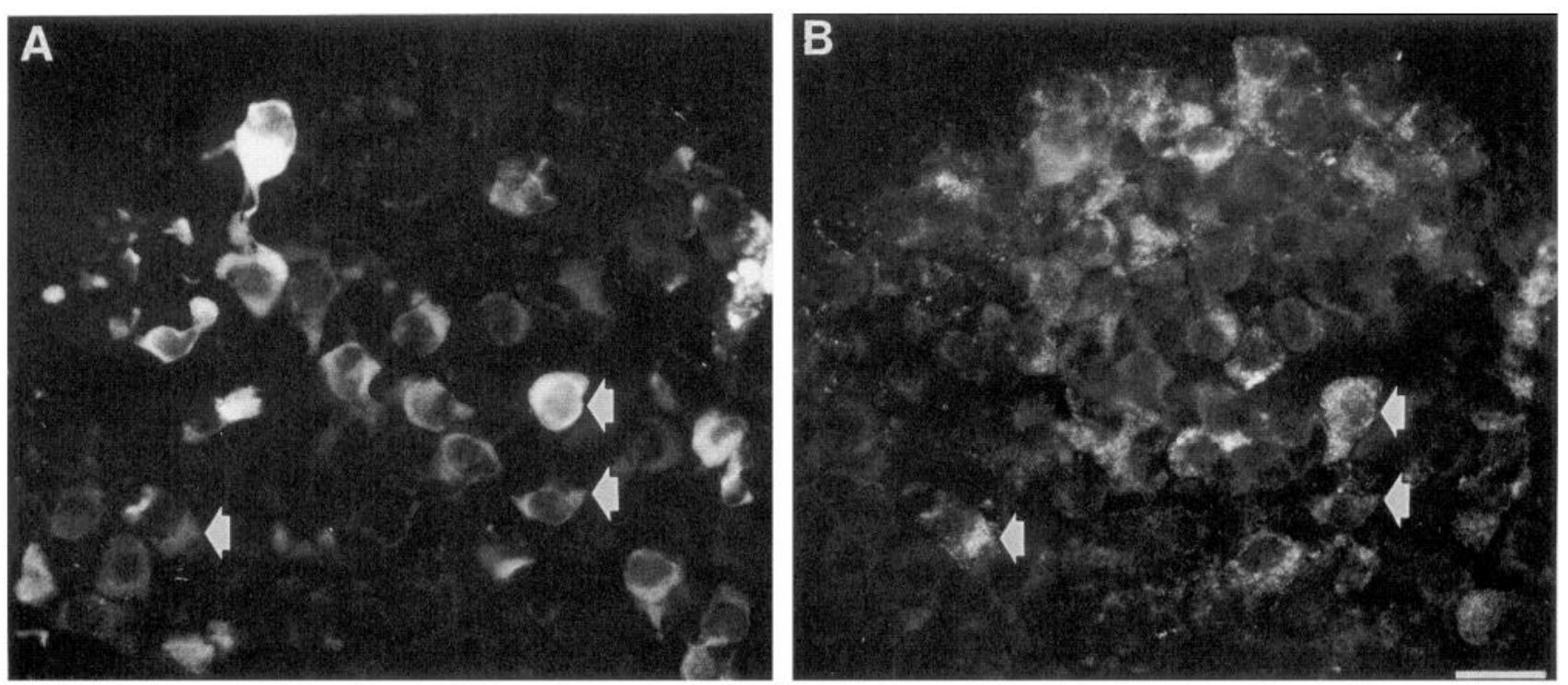

Figure 8. Fluorescence photomicrographs of a tissue section through an E14.5 JSG grown for $4 \mathrm{~d}$ in explant culture, double immunostained for $\mathrm{TH}(A)$ and $\mathrm{SP}(B)$. Arrows indicate double-labeled cells. Many cells that are either $\mathrm{TH}^{+}$or $\mathrm{SP}^{+}$, but not double stained, are also present. Scale bar, $40 \mu \mathrm{m}$.

Many of these cells expressed TH (Fig. 9B). In contrast, E16.5 ganglia grown for $24 \mathrm{hr}$ in explant culture remained as a coherent cell mass, with abundant neurite outgrowth and support cell migration, but no neuronal migration (Fig. 9C). These observations raised the possibility that TH expression by JSG neurons might be related to their state of aggregation. To test this possibility, E16.5 and older JSG were dissociated into dispersed cell cultures and monitored for their expression of $\mathrm{TH}$ after 24 $\mathrm{hr}$ in vitro. Although only a small number of neurons survived in the absence of NGF at this age, approximately $20 \%$ were TH-
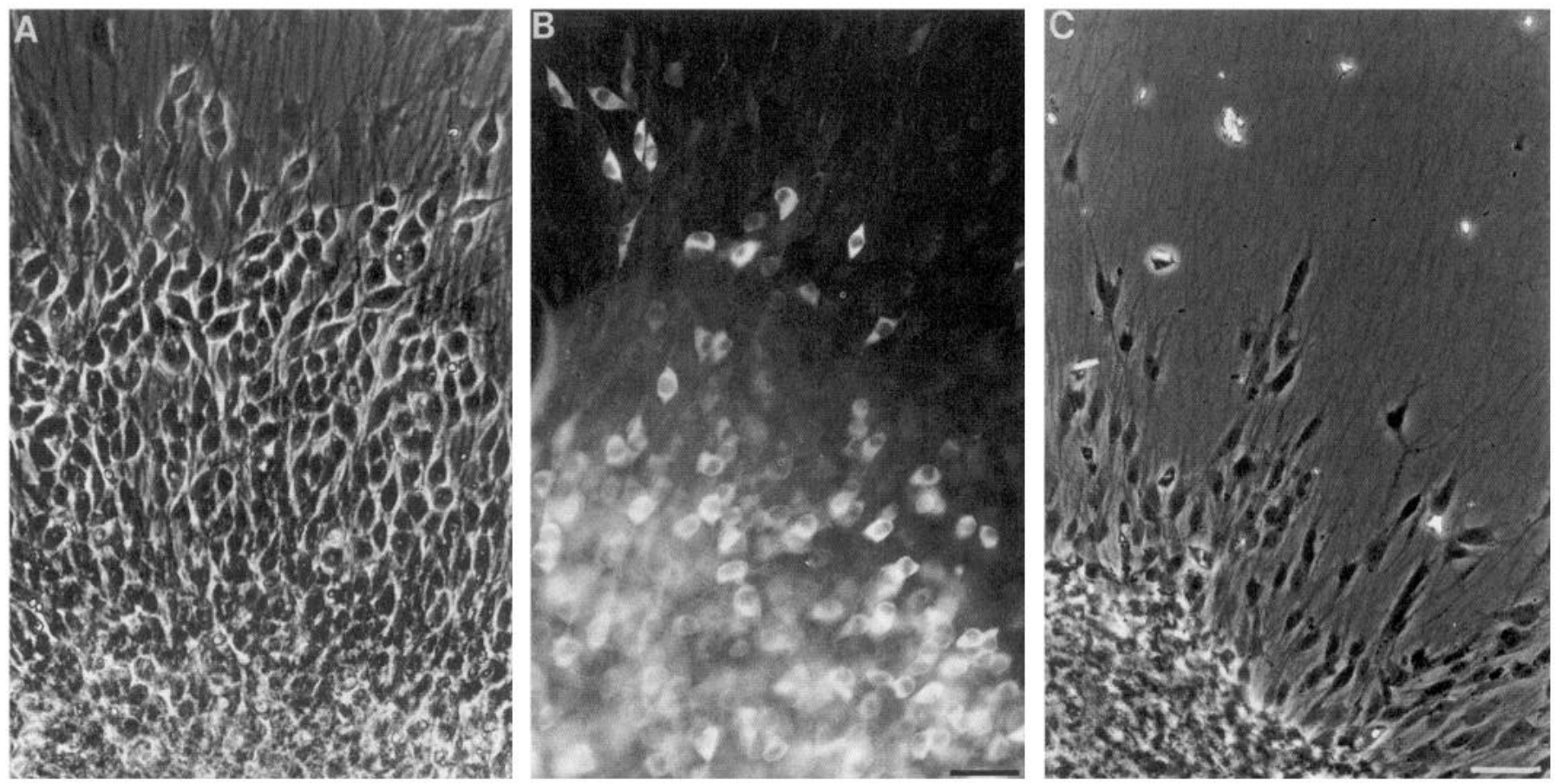

Figure 9. Comparison of neuronal migration in $24 \mathrm{hr}$ explant cultures of E13.5 ( $A$ and $B)$ and E16.5 (C) JSG grown in the presence of $20 \mathrm{ng} / \mathrm{ml}$ NGF. $A$, Phase-contrast photomicrograph showing neurons dispersed beyond the border (phase-bright region at bottom) of an E13.5 explant. Neurites and dark, flat non-neuronal cells can be seen distal to the migrating cells at the top of the figure. $B$, An E13.5 JSG culture, similar to that shown in $A$, immunostained for TH. Note the immunoreactive neurons dispersed beyond the border of the explant. $C$, Phase-contrast photomicrograph showing neurite outgrowth and non-neuronal cell migration away from the border of an E16.5 JSG explant. Note the absence of neurons in the halo surrounding the explant; the non-neuronal phenotype of the phase-dark cells was confirmed by their lack of NF protein immunoreactivity (not shown). Scale bars: $A$ and $C, 46 \mu \mathrm{m} ; B, 40 \mu \mathrm{m}$. 

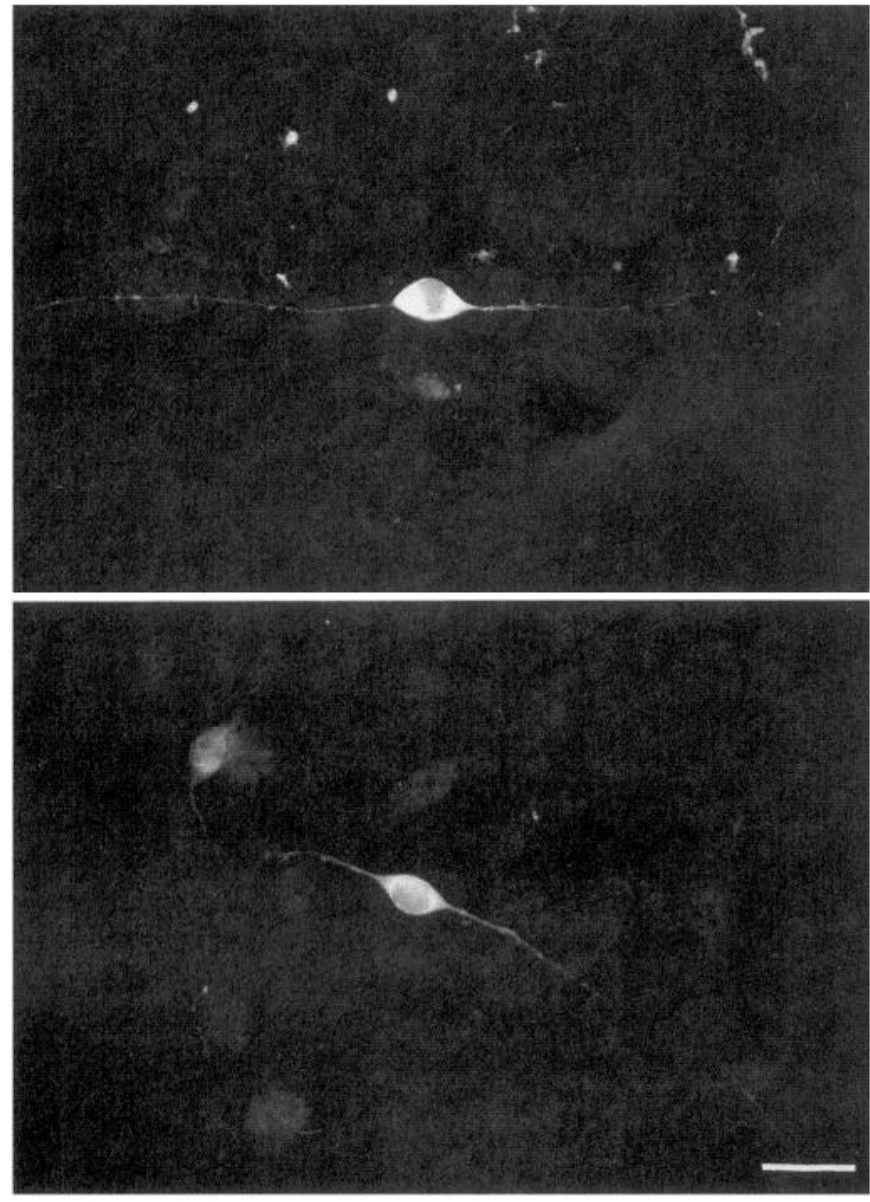

Figure 10. High-magnification fluorescence photomicrographs of THimmunoreactive neurons in $24 \mathrm{hr}$ dissociate cell cultures of E16.5 JSG grown in the absence of NGF. Note the bipolar morphology of the cells, similar to that seen in E14.5 JSG dissociates (compare with Fig. 4). Scale bar, $20 \mu \mathrm{m}$.

positive (Table 1), compared to less than $1 \%$ in the JSG in situ or in $24 \mathrm{hr}$ explant cultures (not shown). These mostly bipolar cells exhibited NF protein immunoreactivity, gave rise to long processes, and appeared identical to the TH cells seen in E14.5 dissociates (Fig. 10; compare with Fig. 4). As with younger ganglia, treatment with NGF resulted in a greater than twofold increase in the proportion of $\mathrm{TH}$ cells compared to controls (Table 1). Similar results were obtained with E16.5 DRG and trigeminal ganglion cultures (data not shown). These data indicated that although TH cells were virtually never seen in E16.5 ganglia in vivo or in explant culture, cells capable of expressing the phenotype were still present at this age.

\section{TH cells in newborn sensory ganglia}

The fact that cells capable of expressing TH were present in the E16.5 JSG, after the end of detectable TH expression in vivo, prompted us to ask whether or not this capability persisted throughout ganglion development. To address this question, newborn (postnatal day 3) JSG were grown in dissociate culture with NGF (20 ng/ml) and monitored for TH expression as before. As with the E16.5 ganglion, a subset of sensory neurons in these cultures were $\mathrm{TH}$ positive. The proportion of $\mathrm{TH}$ cells in these cultures appeared less than at E16.5. Moreover, cells in the newborn ganglia had undergone considerable morphologic differentiation compared to younger ages, enabling us to distinguish among several different subpopulations of neurons. The TH neurons appeared to fall within two distinct morphologic subtypes: small unipolar cells with strong TH immunoreactivity (Fig. 11A) and a second population of intermediatesized cells (Fig. $11 B$ ). TH was never seen in the largest ganglion neurons. These observations suggest that the ability to express TH persists in the JSG until at least the first postnatal week and is restricted to specific subclasses of JSG sensory neurons. Moreover, the fact that TH expression was seen in E16.5 and newborn ganglion dissociates and not explants suggested that the state of aggregation of embryonic ganglion cells could influence expression of this phenotype.

\section{TH expression and cell aggregation}

To test the role of cell aggregation in transmitter expression directly, dissociate cultures of E16.5 JSG were grown at different densities and monitored for expression of TH. JSG dissociates were plated at concentrations of approximately 2, 8, and 16 ganglia per culture well (Fig. 12), grown for $24 \mathrm{hr}$ in the presence of NGF $(5-20 \mathrm{ng} / \mathrm{ml})$, and then processed for simultaneous
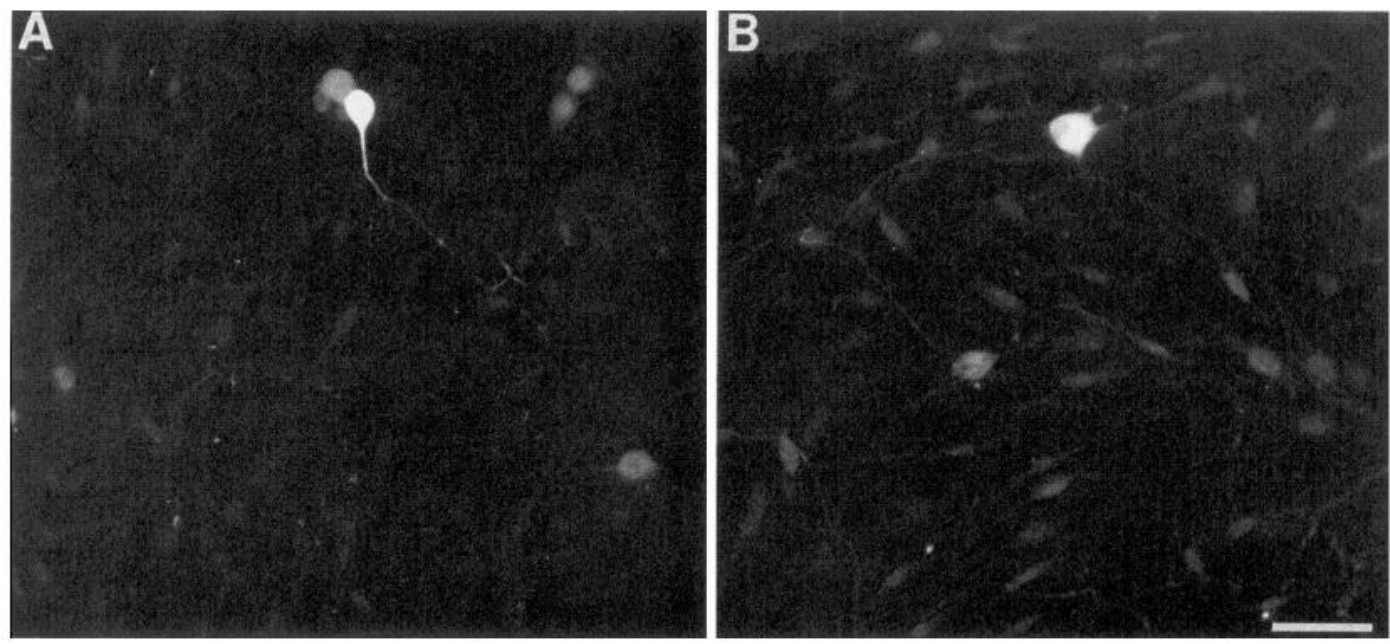

Figure 11. Fluorescence photomicrographs showing TH-immunoreactive neurons in $24 \mathrm{hr}$ dissociated cell cultures of newborn (postnatal day 3 ) JSG. Scale bar, $40 \mu \mathrm{m}$. 
Table 3. Effect of cell density on the number of TH neurons in

\section{E16.5 JSG cultures}

\begin{tabular}{llll}
$\begin{array}{l}\text { Ganglia/ } \\
\text { well }\end{array}$ & $\mathrm{TH}^{+}(n)$ & $\mathrm{NF}^{+}(n)$ & $\begin{array}{l}\mathrm{TH}^{+} / \mathrm{NF}^{+} \\
\times 100 \%\end{array}$ \\
\hline 2 & $728 \pm 32$ & $2,240 \pm 72$ & $32 \%$ \\
& $(5)$ & $(5)$ & \\
8 & $2491 \pm 132$ & $11,444 \pm 250$ & $22 \% *$ \\
& $(4)$ & $(4)$ & \\
16 & $3687 \pm 118$ & $17,885 \pm 330$ & $21 \%^{*}$ \\
& $(3)$ & $(3)$ & \\
\hline
\end{tabular}

$\overline{\text { Each value represents the mean } \pm \text { SEM of cell counts from } n \text { cultures, plated at }}$ the density indicated on the left.

*, Significantly different from controls ( 2 ganglia/well) by both parametic $(p<$ $0.01)$ and nonparametic $(p<0.05)$ ANOVA.

visualization of TH- and NF protein-immunoreactive neurons. Observation of these cultures by phase-contrast microscopy indicated that cells tended to cluster in larger groups with increasing cell density (Fig. 12). Cell counts revealed a significant $30 \%$ decrease in the percentage of $\mathrm{TH}$-containing neurons in high density ( 8 and 16 ganglia per well) versus low density ( 2 ganglia per well) cultures (Table 3 ). In addition, the reduction in the proportion of $\mathrm{TH}$ neurons in high-density cultures was associated with changes in neuronal morphology. Whereas most $\mathrm{TH}$ cells in low-density cultures exhibited relatively immature bipolar morphologies as before (see Fig. 10), many TH neurons in high-density cultures had unipolar morphologies characteristic of older ganglion cells (Fig. 13A; compare with Fig 11 $A$ ). In addition, high-density cultures contained a subset of intermediate-sized TH cells similar to those seen in more mature ganglia (Fig. 13B; compare with Fig. 11B).

\section{Discussion}

Our findings demonstrate that a large subset of primary sensory neurons in crest-derived cranial ganglia of the rat exhibit the ability to express TH. Although TH is only transiently detectable at early stages in vivo, cells capable of expressing this phenotype in culture persist in sensory ganglia until at least the first postnatal week. After E16.5, however, TH is detectable only when ganglia are dissociated into single cells, suggesting that cell aggregation may attenuate expression of this phenotype. Consistent with this hypothesis, reaggregation of cells by increasing cell density in dissociate culture decreased the proportion of $\mathrm{TH}$ neurons.

\section{TH cells in embryonic rat cranial ganglia are primary sensory neurons}

Previous studies on TH localization in mature sensory ganglia demonstrated that the ability of peripheral neurons to express catecholaminergic transmitter traits stably is not restricted to sympathoadrenal derivatives of the neural crest. Rather, this phenotype is also characteristic of specific subsets of primary sensory neurons (Katz et al., 1983; Price and Mudge, 1983; Katz and Black, 1986). Moreover, the finding that TH is transiently expressed by cells with a widespread distribution in embryonic sensory ganglia raised the possibility that many sensory neurons were capable of expressing selected CA traits during early stages of development (Jonakait et al., 1984; Katz and Erb, 1990a). However, this interpretation was constrained by the fact that the cellular phenotype of transient TH cells was unknown; the
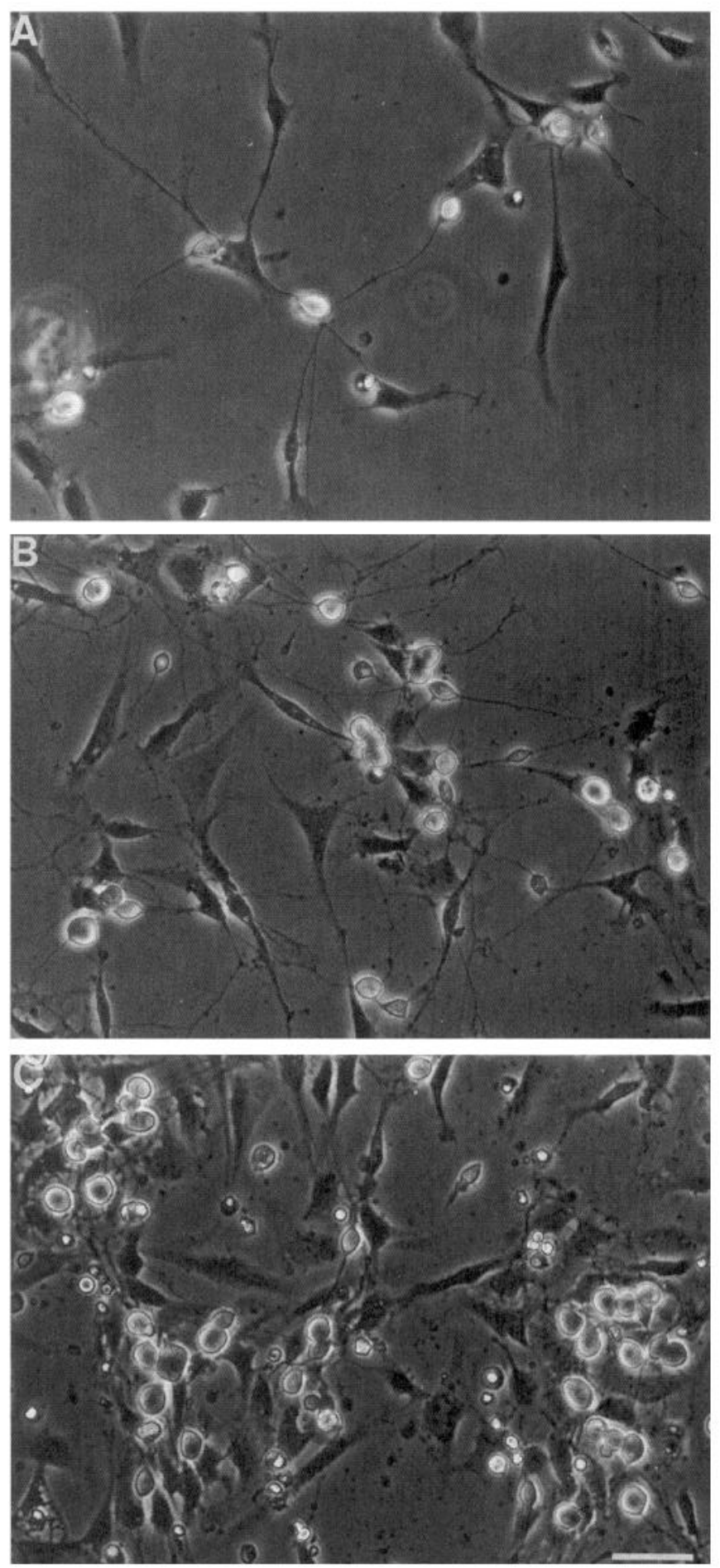

Figure 12. Phase-contrast photomicrographs of E16.15 JSG dissociate cell cultures grown for $24 \mathrm{hr}$ at densities of $2(A), 8(B)$, and $16(C)$ ganglia per well in the presence of $20 \mathrm{ng} / \mathrm{ml} \mathrm{NGF}$. Note the increase in size of cellular aggregates with increased plating density. Scale bar, 46 $\mu \mathrm{m}$.

mammalian neural crest gives rise to multiple cell types, for example, including sympathoadrenal and enteric precursors (Baetge and Gershon, 1990a,b), that are capable of expressing CA properties. Similarly, studies of embryonic avian sensory ganglia demonstrated the presence of apparently uncommitted 

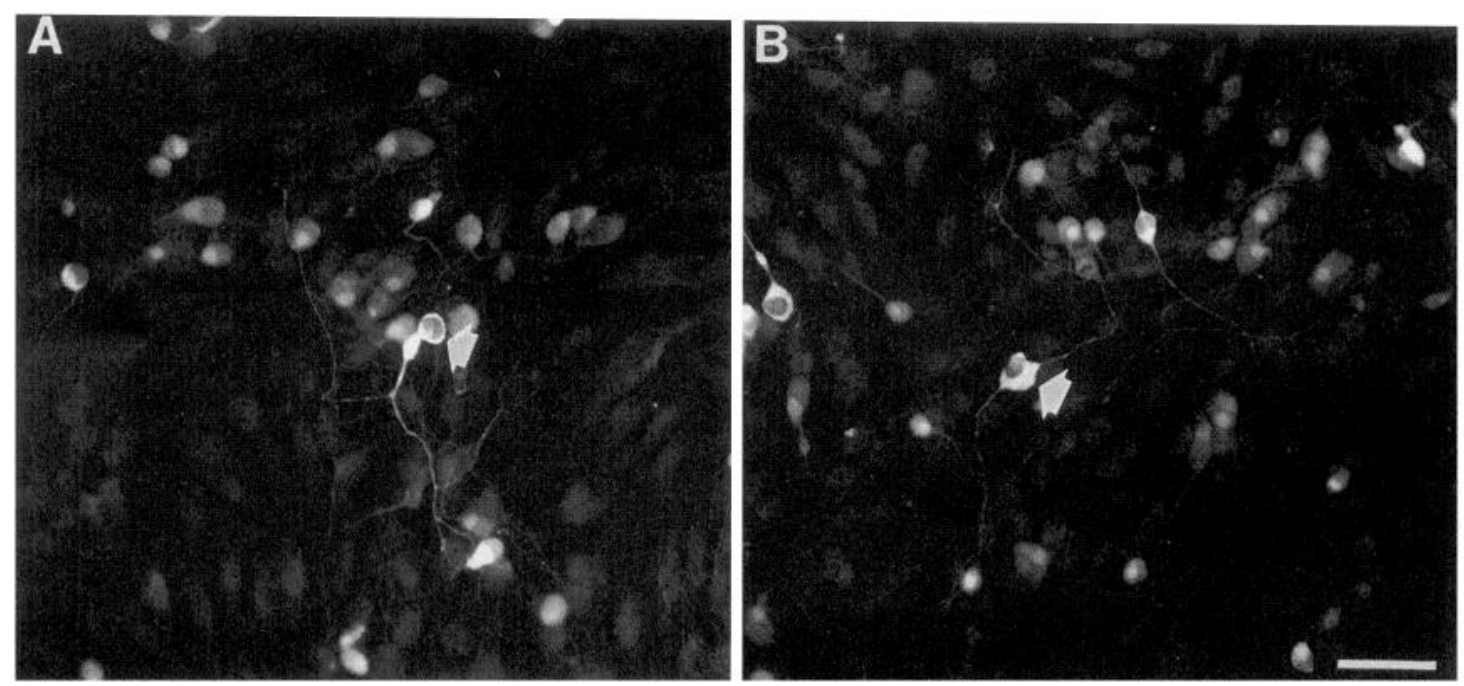

Figure 13. Fluorescence photomicrographs showing TH-immunoreactive neurons in high-density (16 ganglia/well) dissociate cell cultures of E16.5 JSG. Cells exhibit more differentiated morphologies than those seen in low-density cultures (compare with Fig. 10), including small unipolar $(A)$ and intermediate-sized bipolar $(B)$ forms. Scale bar, $40 \mu \mathrm{m}$.

precursor cells that give rise to a CA autonomic phenotype under selected conditions in culture (Xue et al., 1985, 1987, 1988; Ziller et al., 1987; LeBlanc, 1990) and after heterochromic transplantation in ovo (Ayer-LeLievre and LeDouarin, 1982). The TH cells described in the present study are clearly distinct, however, from sympathoadrenal and enteric precursors. TH neurons in the JSG, for example, exhibit sensory neuron morphologies and do not express immunoreactivity to monoclonal antibody SA1, a specific marker for embryonic sympathoadrenal and enteric precursor cells. Our data also indicate marked differences between the TH sensory neurons described here and latent autonomic precursors previously described in cultures of avian sensory ganglia. Unlike the cells in the rat JSG and DRG, for example, TH cells are never seen in avian sensory ganglia in vivo (Xue et al., 1985) and only appear in vitro after prolonged times in culture (Xue et al., 1985; Ziller et al., 1987; LeBlanc, 1990) in the presence of specific additives, such as chick embryo extract (Ziller et al., 1987; Xue et al., 1988; see also Howard and Bronner-Fraser, 1985, 1986). In addition, TH cells that appear in avian sensory ganglia cultures are morphologically distinct from sensory neurons in that they do not express NF proteins and are multipolar (Xue et al., 1985; LeBlanc, 1990). In contrast, the TH cells described in the present study are NFpositive, in vivo and in vitro, and exhibit uni- and bipolar morphologies typical of sensory neurons. Moreover, TH cells in avian DRG cultures arise from cycling precursors (Xue et al., 1985), whereas the TH sensory neurons in rat cranial ganglia do not divide in culture. Finally, TH cells in avian sensory ganglion cultures appear insensitive to NGF (Xue et al., 1985), in marked contrast to the cells observed in our cultures. The apparent absence of TH-containing sensory neurons in chick suggests that the repertoire of neuronal phenotypes in mammalian and avian sensory ganglia is not necessarily homologous. This is consistent with recent findings from our laboratory indicating that trophic requirements may also differ among mammalian and avian cranial sensory neurons (Katz et al., 1990).

\section{Developmental regulation of $T H$ expression}

Our studies with E16.5 and older ganglia indicate that a subset of JSG neurons is capable of expressing $\mathrm{TH}$ after the period of transient expression in vivo. Moreover, the fact that $\mathrm{TH}$ sensory neurons were also seen in E16.5 cranial DRG and trigeminal ganglion dissociates indicates that this potential is a feature of cells distributed throughout the cranial sensory neuraxis. It seems highly unlikely, therefore, that the loss of TH after the period of transient expression in vivo can be attributed to a loss of cells capable of expressing a CA phenotype. Rather, our data suggest that the TH sensory neurons observed during early gangliogenesis in vivo undergo a change in phenotype and lose detectable expression of TH around E16.5. An alternative possibility, however, is that the embryonic ganglia contain two different populations of TH neurons: those that transiently express $\mathrm{TH}$ before E16.5 and those that express $\mathrm{TH}$ in dissociate cultures of older ganglia. The loss of $\mathrm{TH}$ after E16.5 in vivo could therefore be explained by migration of the early, transient cells combined with the failure of TH-competent cells that remain in the ganglion to express a CA phenotype. The fact that transient $\mathrm{TH}$ neurons were seen dispersed at the margins of the E14.5 JSG in situ suggests that some of these cells may indeed migrate to more distal sites. Nonetheless, the marked similarities in size, morphology, and NGF responsiveness among $\mathrm{TH}$ neurons in cultures of E14.5 and E16.5 JSG suggest that the cells belong to the same subpopulation of ganglion neurons.

The ability to express $\mathrm{TH}$ appears to be restricted to specific subtypes of cranial sensory neurons. Even when expression was stimulated with exogenous NGF, for example, no more than $43 \%$ of cells in E16.5 JSG cultures exhibited detectable TH immunostaining. Moreover, at postnatal ages, when ganglion cells had acquired distinguishing morphologic features, TH immunoreactivity was found exclusively in small and intermediate-sized cells. In situ, many small JSG cells express peptidergic properties, such as SP (Katz and Karten, 1980). SP immunoreactivity appears in the JSG in situ on E16.5 (Ayer-LeLievre and Sieger, 1984), that is, immediately after the period of transient TH expression. These findings raise the possibility that transient $\mathrm{TH}$ cells may acquire a peptidergic phenotype after the loss of CA traits. This possibility is supported by our finding that when $\mathrm{TH}$ expression was prolonged in long-term explant cultures of E14.5 ganglia, some sensory neurons coexpressed both TH and SP. 


\section{TH expression and cell aggregation}

Three lines of evidence indicate that the lack of detectable $\mathrm{TH}$ expression in JSG and cranial DRG neurons after E16.5 in vivo may be related to factors associated with cell aggregation. First, transient $\mathrm{TH}$ expression is restricted to the earliest stages of gangliogenesis, when crest cells are still actively migrating. In fact, transient $\mathrm{TH}$ cells are often seen dispersed beyond the borders of the developing JSG, extending into the distal ganglia of the glossopharyngeal-vagal complex (Fig. 2A). Moreover, at later stages, when $\mathrm{TH}$ is no longer seen in vivo, the phenotype rapidly reappears when intact ganglia are dissociated into dispersed cell cultures. Expression appears to be specifically related to dissociation, rather than other factors in the culture environment, because TH cells are only rarely seen after E16.5 in explant cultures grown under identical conditions. Finally, reaggregation of dissociated ganglion cells by growth at high densities decreases the proportion of $\mathrm{TH}$-containing neurons.

A role for cell aggregation in modulating $\mathrm{TH}$ expression is consistent with several recent reports of transmitter phenotypic regulation by cell density in sympathetic neuron and adrenal chromaffin cultures (Acheson and Thoenen, 1983; Adler and Black, 1985; Kessler, 1985; Adler, 1989). Studies of sympathetic neurons indicate that increasing density and cell membrane contact results in a dramatic increase in levels of SP (Adler and Black, 1985; Kessler, 1985) and somatostatin (Kessler, 1985) immunoreactivity and ChAT catalytic activity per cell (Adler and Black, 1985), whereas TH activity per cell falls (Lee et al., 1990) or remains constant (Adler and Black, 1985; Kessler, 1985). Contact-mediated alterations in sympathetic transmitter phenotype appear to be regulated by one or more membraneassociated proteins expressed by neuronal and non-neuronal cells (Kessler, 1985; Adler and Black, 1986; Kessler et al., 1986; Wong and Kessler, 1987; Adler, 1989; Lee et al., 1990; see also Hawrot, 1980). Interestingly, Adler (1989) and Lee et al. (1990) reported that sensory ganglia contained high levels of a membrane-associated activity similar to that found in sympathetic ganglia, suggesting that such molecules may play a role in regulating sensory, as well as sympathetic, transmitter phenotype. This does not rule out the possibility that other mechanisms, including soluble factors and extracellular matrix components (Maxwell and Forbes, 1987) that may be present in the intact sensory ganglia, also play a role in regulating transmitter phenotype. For example, ciliary neurotrophic factor (Barbin et al., 1984), cholinergic differentiation factor (Fukada, 1985), and an activity recently identified in extracts of rat sweat glands (Rao and Landis, 1990) all decrease TH levels in sympathetic neuron cultures.

Our experiments indicate that TH expression is not the only neuronal trait that may be regulated by cell aggregation in sensory ganglion cultures. Neurons in high-density cultures, for example, exhibited a degree of morphologic differentiation not seen in cultures grown at low density. In particular, TH cells in high-density cultures seemed to segregate into at least two classes: small pseudounipolar cells with strong immunoreactivity and intermediate-sized cells with moderate levels of TH staining. These two cell types are characteristic of sensory neurons in cultures of older ganglia; in contrast, neurons in low-density cultures exhibited relatively immature bipolar morphologics and more homogeneous levels of TH staining. Previous studies by Mudge (1984) demonstrated that development of a unipolar morphology in cultured sensory neurons was dependent on con- tact with ganglionic non-neuronal cells. Although we do not yet know whether common mechanisms mediate neurochemical and morphologic development, our findings indicate that the decrease in TH expression seen during cranial sensory maturation in vivo, and in high-density cultures in vitro, may be only one facet of a more general program of sensory neuron differentiation associated with cell aggregation in developing ganglia.

\section{References}

Acheson AL, Thoenen $\mathrm{H}$ (1983) Cell contact-mediated regulation of tyrosine hydroxylase synthesis in cultured bovine adrenal chromaffin cells. J Cell Biol 97:925-928.

Adelmann HB (1925) The development of the neural folds and cranial ganglia of the rat. J Comp Neurol 39:19-172.

Adler JE (1989) Neuronal aggregation and neurotransmitter regulation: partial purification and characterization of a membrane-derived factor. Int J Dev Neurosci 7:533-538.

Adler JE, Black IB (1985) Sympathetic neuron density differentially regulates transmitter phenotypic expression in culture. Proc Natl Acad Sci USA 82:4296-4300.

Adler JE, Black IB (1986) Membrane contact regulates transmitter phenotypic expression. Dev Brain Res 30:237-241.

Altman J, Bayer SA (1982) Development of the cranial nerve ganglia and related nuclei in the rat. Adv Anat Embryol Cell Biol 74:1-87.

Anderson DJ, Carnahan J, Michelsohn A, Patterson PH (1991) Antibody markers identify a common progenitor to sympathetic neurons and chromaffin cells in vivo, and reveal the timing of commitment to neuronal differentiation in the sympathoadrenal lineage. $J$ Neurosci $11: 3507-3519$

Ayer-LeLievre CS, LeDouarin NM (1982) The early devclopment of cranial sensory ganglia and the potentialities of their component cells studied in quail-chick chimeras. Dev Biol 94:291-311.

Ayer-LeLievre CS, Seiger A (1984) Development of substance Pimmunoreactive neurons in cranial sensory ganglia of the rat. Int J Dev Neurosci 2:451-463.

Baetge G, Pintar JE, Gershon MD (1990a) Transiently catecholaminergic (TC) cells in the bowel of the fetal rat: precursors of noncatecholaminergic enteric neurons. Dev Biol 141:353-380.

Baetge G, Schneider KA, Gershon MD (1990b) Development and persistence of catecholaminergic neurons in cultured explants of fetal murine vagus nerves and bowel. Development 110:689-701.

Barbin G, Manthorpe M, Varon S (1984) Purification of chick eye ciliary neurotrophic factor. J Neurochem 43:1468-1478.

Batten EH (1957) The cpibranchial placode of the vagus nerve in the sheep. J Anat 91:471-489.

Carnahan JF, Patterson PH (1991a) The generation of monoclonal antibodies that bind preferentially to adrenal chromaffin cells and the cells of embryonic sympathetic ganglia. J Neurosci 11:3493-3506.

Carnahan JF, Patterson PH (1991b) Isolation of the progenitor cells of the sympathoadrenal lineage from embryonic sympathetic ganglia with the SA monoclonal antibodies. J Neurosci 11:3520-3530.

D'Amico-Martel A, Noden DM (1983) Contributions of placodal and neural crest cells to avian cranial peripheral ganglia. Am J Anat 166: 445-468.

Dodd J, Jessell TM (1985) Lactoseries carbohydrates specify subsets of dorsal root ganglion neurons projecting to the superficial dorsal horn of rat spinal cord. J Neurosci 5:3278-3294.

Dodd J, Jessell TM (1986) Cell surface glycoconjugates and carbohydrate-binding proteins: possible recognition signals in sensory neurone development. J Exp Biol 124:225-238.

Fukada K (1985) Purification and partial characterization of a cholinergic differentiation factor. Proc Natl Acad Sci USA 82:8795-8799.

Hawrot E (1980) Cultured sympathetic neurons: effects of cell-derived and synthetic substrata on survival and development. Dev Biol 74: 136-151.

Howard MJ, Bronner-Fraser M (1985) The influence of neural tubederived factors on differentiation of neural crest cells in vitro: I. Histochemical study on the appearance of adrenergic cells. J Neurosci 5: 3302-3309.

Howard MJ, Bronner-Fraser M (1986) Neural tube-derived factors influence differentiation of neural crest cells in vitro: effects on activity of neurotransmitter biosynthetic enzymes. Dev Biol 117:45-54.

Johnston MC (1966) A radioautographic study of the migration and 
fate of cranial neural crest cells in the chick embryo. Anat $\operatorname{Rec} 156$ : $143-146$.

Jonakait GM, Markley KA, Goldstein M, Black IB (1984) Transient expression of selected catecholaminergic traits in cranial sensory and dorsal root ganglia of the embryonic rat. Dev Biol 101:51-60.

Katz DM, Black IB (1986) Expression and regulation of catecholaminergic traits in primary sensory neurons: relationship to target innervation in vivo. J Neurosci 6:983-989.

Katz DM, Erb M (1990a) Development regulation of tyrosine hydroxylase expression in primary sensory neurons of the rat. Dev Biol 137:233-242.

Katz DM, Erb M (1990b) Catecholaminergic differentiation in embryonic rat cranial sensory ganglia: possible role of nerve growth factor. Soc Neurosci Abstr 16:1273.

Katz DM, Karten HJ (1980) Substance P in the vagal sensory ganglia: localization in cell bodies and pericellular arborizations. J Comp Neurol 193:549-564.

Katz DM, Markey KA, Goldstein M, Black IB (1983) Expression of catecholaminergic characteristics by primary sensory neurons in the normal adult rat in vivo. Proc Natl Acad Sci USA 80:3526-3530.

Katz DM, Erb M, Lillis R, Neet K (1990) Trophic regulation of nodose ganglion cell development: evidence for an expanded role of nerve growth factor during embryogenesis in the rat. Exp Neurol 110:1-10.

Kessler JA (1985) Differential regulation of peptide and catecholamine characters in cultured sympathetic neurons. Neuroscience 15:827839.

Kessler JA, Black IB (1980) The effects of nerve growth factor (NGF) and antiserum to NGF on the development of embryonic sympathetic neurons in vivo. Brain Res 189:157-168.

Kessler JA, Conn G, Hatcher VB (1986) Isolated plasma membranes regulate neurotransmitter expression and facilitate effects of a soluble brain cholinergic factor. Proc Natl Acad Sci USA 83:3528-3532.

Laemmli UK (1970) Cleavage of structural proteins during the assembly of the head of bacteriophage T4. Nature 227:680-685.

Lawson SN, Caddy KWT, Biscoe TJ (1974) Development of rat dorsal root ganglion neurones. Studies of cell birthdays and changes in mean cell diameter. Cell Tissue Res 153:399-413.

Leblanc GG (1990) Coexpression of sensory and autonomic neurotransmitter traits by avian neural crest cells in vitro. J Neurobiol 21 : $567-577$.

LeDouarin NM, Smith J, LeLievre CS (1981) From the neural crest to the ganglia of the peripheral nervous system. Annu Rev Physiol 43:653-671.

Lee J-M, Alder JE, Black IB (1990) Regulation of neurotransmitter expression by a membrane-derived factor. Exp Neurol 108:109-1 13.

Mains RE, Patterson PH (1973) Primary cultures of dissociated sympathetic neurons. I. Establishment of long-term growth in culture and studies of differentiated properties. J Cell Biol 59:329-345.

Marusich MF, Pourmehr K, Weston JA (1986a) A monoclonal antibody (SN1) identifies a subpopulation of avian sensory neurons whose distribution is correlated with axial level. Dev Biol 118:494 504.

Marusich MF, Pourmehr K, Weston JA (1986b) The development of an identified subpopulation of avian sensory neurons is regulated by interaction with the periphery. Dev Biol 118:505-510.
Maxwell GD, Forbes ME (1987) Exogenous basement-membrane-like matrix stimulates adrenergic development in avian neural crest cultures. Development 101:767-776.

Mudge AW (1984) Schwann cells induce morphological transformation of sensory neurones in vitro. Nature 309:367-369.

Nagy JI, Hunt SP (1982) Fluoride-resistant acid phosphatase-containing neurones in dorsal root ganglia are separate from those containing substance $P$ or somatostatin. Neuroscience 7:89-97.

Nagy JI, Hunt SP (1983) The termination of primary afferents within the rat dorsal horn: evidence of rearrangement following capsaicin treatment. J Comp Neurol 218:145-158.

Narayanan CH, Narayanan Y (1980) Neural crest and placodal contributions in the development of the glossopharyngeal-vagal complex in the chick. Anat Rec 196:71-82.

Noden DM (1978) The control of avian aphalic neural crest cytodifferentiation. II. Neural tissues. Dev Biol 67:313-329.

Price J, Mudge AW (1983) A subpopulation of rat dorsal root ganglion neurones is catecholaminergic. Nature 301:241-243.

Rambourg A, Clermont Y, Beaudet A (1983) Ultrastructural features of six types of neurons in rat dorsal root ganglia. J Neurocytol 12: $47-66$.

Rao MS, Landis SC (1990) Characterization of target-derived neuronal cholinergic differentiation factors. Neuron 5:899-910.

Regan LJ, Dodd J, Barondes SH, Jessell TM (1986) Selective expression of endogenous lactose-binding lectins and lactoseries glycoconjugates in subsets of rat sensory neurons. Proc Natl Acad Sci USA $83: 2248-2252$.

Rohrer H (1985) Nonneuronal cells from chick sympathetic and dorsal root sensory ganglia express catecholamine uptake and receptors for nerve growth factor during development. Dev Biol 111:95-107.

Smith AP, Greene LA, Fish HR, Varon S, Shooter EM (1969) Subunit equilibria of the 7S nerve factor protein. Biochemistry 8:4918-4926.

Stach RW, Wagner BJ, Stach BM (1977) A more rapid method for the isolation of the $7 \mathrm{~S}$ nerve growth factor complex. Anal Biochem 83:26-32.

Weston J (1970) The migration and differentiation of neural crest cells. Adv Morphog 8:41-114.

Wong V, Kessler IA (1987) Solubilization of a membrane factor that stimulates levels of substance $P$ and choline acetyltransferase in sympathetic neurons. Proc Natl Acad Sci USA 84:8726-8729.

Xue ZG, Smith J, LeDouarin NM (1985) Differentiation of catecholaminergic cells in cultures of embryonic avian sensory ganglia. Proc Natl Acad Sci USA 82:8800-8804.

Xue ZG, Smith J, LeDouarin NM (1987) Developmental capacities of avian embryonic dorsal root ganglion cells: neuropeptides and tyrosine hydroxylase in dissociated cell cultures. Dev Brain Res 34: 99-109.

Xue ZG, LeDouarin NM, Smith J (1988) Insulin and insulin-like growth factor-I can trigger the differentiation of catecholaminergic precursors in cultures of dorsal root ganglia. Cell Differ Dev 25:1-10.

Ziller C, Fauquet M, Kalcheim C, Smith J, LeDouarin NM (1987) Cell lineages in peripheral neurons system ontogeny: medium-induced modulation of neuronal phenotypic expression in neural crest cell cultures. Dev Biol 120:101-111. 